\title{
Behavioural problems among schoolchildren in Nigeria
}

\author{
M U Akpan, MB BCh, FWACP \\ Department of Paediatrics, University of Uyo Teaching \\ Hospital, Uyo, Akwa-lbom State, Nigeria
}

N C Ojinnaka, MB BS, FWACP

Department of Paediatrics, University of Nigeria Teaching Hospital, Enugu, Enugu State, Nigeria

\section{E Ekanem, MB BCh, FMCPaed}

Department of Paediatrics, University of Uyo Teaching Hospital

Background. Behavioural problems among schoolchildren can pose a burden on families and society.

Objective. To determine the prevalence and pattern of behavioural problems among children living in Uyo, a town in South-South Nigeria.

Methods. A cross-sectional study was carried out among 572 pupils from six primary schools selected randomly from private and government schools in Uyo. Pupils with a normal $I Q$ were selected using a systematic sampling method. The Rutter behavioural scale for teachers (B2) was completed by their teachers, and that for parents (A2) was completed by the parents. Student's ktest was used to compare pairs of means, frequencies were compared using the chi-square test, and $p<0.05$ was taken as significant.

Results. According to the teachers' scale 132 pupils (23.1\%) had scores within the range indicating behavioural problems, compared with 103 pupils (18.0\%) on the parents' scale. This was statistically significant $\left(\chi^{2}=19.8, p=0.001\right)$. Pupils in government and private schools had mean scores of 7.4 (standard deviation (SD) 6.41) and 5.12 (SD 6.26) and 7.29 (SD 5.84) and 6.96 (SD 5.76), respectively. Behavioural problems were more common among children in government schools and among those in the lower socio-economic class. Boys had significantly higher mean scores than girls, and both scales showed more boys to be disturbed. Antisocial behaviour was commonest among boys and older children.

Conclusion. There is a high prevalence of behavioural problems among primary school children in Uyo, with a predominance of antisocial behaviour. The government needs to provide appropriate services to deal with this state of affairs.

Behavioural problems in children can be part of normal development. Such problems are often transient and may not even be noticed, and may be exhibited in certain settings and not in others (e.g. at home and not at school). In developed countries parents tend to seek advice even for minor problems, such as persistent thumb sucking, while in developing countries major psychiatric disorders such as childhood schizophrenia may go unattended. Some schoolchildren exhibit a range of deviant behaviour that may be a burden not only for parents and families, but also for teachers, other pupils and even the community. ${ }^{1.7}$ It has been reported that about $10-26 \%$ of children in both developed and developing countries have behavioural problems, and a single child can have a range of problems., 30.8 However, the prevalence varies widely depending on geographical location, culture, family characteristics and socio-economic setting. ${ }^{3,5}$ Standardised scales have been developed for the assessment of behavioural problems in children in developed countries. ${ }^{9-11}$ The Rutter teachers' and parents' scales for assessment of behavioural problems have been standardised for use on Nigerian children. 3,12 These scales have been used in previous studies to assess the prevalence of behavioural disorders in children in western and south-eastern Nigeria. ${ }^{3,6,8,13,14}$

In the study by Adelekan et al. in Kwara State, Nigeria, 846 parents completed the 31 -item Rutter A2 scale for their children aged 6 - 14 years. ${ }^{14}$ Using the Rutter cut-off point of 13, 18.6\% were found to have a behavioural problem. The prevalence of behavioural problems was also evaluated among 620 United Arab Emirates nationals aged 6 - 18 years; ${ }^{2} 11.8 \%$ scored above the cut-off point, indicating behavioural problems. Conduct problems were more prevalent among boys and emotional problems among girls.

Some researchers have examined whether behavioural symptoms or deviant behaviour among children predict later psychiatric referral. ${ }^{15-17}$ Kumpulainen and Räsänen ${ }^{16}$ assessed a total of 1268 children in Finland at age 8 and again 4 years later, at which time they found that $3.3 \%$ of the study group had been referred for psychiatric consultation. They noted that children who were referred or considered for referral had scored significantly higher on the three questionnaires used for initial assessment - the 
Rutter A2 scale for parents, the Rutter B2 scale for teachers, and the Children's Depression Inventory (CDI).

We set out to determine the prevalence of behavioural problems among children living in Uyo, a town in South-South Nigeria.

\section{Materials and methods}

Uyo is the capital of Akwa Ibom State, one of six states in SouthSouth Nigeria. We studied 572 schoolchildren aged 6 - 12 years from six schools over a 4-month period (April - July 2006).

Ethical approval was obtained from the Ethics Committee of the University of Uyo Teaching Hospital before embarking on the study. Written consent was obtained from the educational board of the state, and verbal consent was obtained from all the head teachers of the selected schools. Informed verbal/written consent was also obtained from the parents of the study subjects.

Primary schools in Uyo were grouped into private and government schools. Three schools were selected from each group by random sampling using the ballot method. For each grade, the ballot method was used to select a class. Six classes were selected from each school. All the pupils from the selected classes were interviewed to identify those with chronic diseases such as sickle cell anaemia, epilepsy, diabetes mellitus and bronchial asthma. Information in this regard was also obtained from the parents. Because these diseases are significantly associated with behavioural disorders, pupils with any history suggestive of such ailments were excluded from the study.

The $I Q$ of each subject was assessed using the Draw-A-Person Test validated for Nigerian children. ${ }^{18}$ Pupils with a score of $\geq 75 \%$, considered a normal score, were included in the study. Eighteen pupils who satisfied the inclusion criteria were selected from each of the classes by a systematic sampling method and constituted the study subjects.

The Rutter behaviour questionnaires, which have been found to be a reliable and valid instrument in a range of socio-cultural settings, were used for this study. The Rutter behaviour questionnaire (B2) for teachers consists of 26 items of behaviour commonly displayed by children, to which the respondent is asked to indicate whether the statement 'certainly applies', 'applies somewhat' or 'does not apply' to the child in question, with respective scores of 2 , 1 or 0 . The total score for an individual child therefore ranges from 0 to 52. A score of 10 and above indicates that a child has behavioural problems. The questionnaires were completed by the children's teachers, who had been trained in use of the questionnaire by one of the authors. To ensure that the teachers had had sufficient contact with the pupils, the study was done in the third term of the academic year. The author was present to answer any questions while the teachers filled in the questionnaires.

Parents of the selected pupils filled out the Rutter behavioural questionnaire for parents (A2). The scale consists of 31 items concerning the child's behaviour, and the parents indicate the extent to which each item applies to the child. Each item is scored 0,1 or 2, as for the teacher questionnaire, so the total score ranges from 0 to 62. A child is considered to have behavioural problems if he/she scores 13 or above. Parents were visited at their homes in the evenings to fill in the questionnaire. The few parents who were not at home were invited to the school to fill it in. The author was available to answer questions, and to translate the items in the questionnaire into the native language for parents who could not speak English. Parents were also asked to state their occupation and educational attainment. Social classification was done using the scheme proposed by Oyedeji, ${ }^{19}$ which is used extensively in the Nigerian environment. Subjects are classified into five grades ( - V) based on their occupational and educational levels. Grade I, which represents the highest social class, comprises senior public servants, professionals, large-scale businessmen and contractors, with university education or its equivalent. Grade II comprises intermediate civil servants and senior school teachers with secondary education and some further training, grade III junior school teachers, drivers and artisans with secondary education, grade IV petty traders, labourers and messengers or other related workers with primary education, and grade V (the lowest social class) the unemployed, students, full-time housewives and subsistence farmers with no formal education. This system was used to assign a social class to each of the subjects, and the grades were then regrouped into upper (I and II), middle (III) and lower (IV and V).

Statistical analysis was done using SPSS version 13. Student's ttest was used to compare pairs of means and the chi-square test for associations. Yates's corrected chi-square test or Fisher's test was used as appropriate. The level of significance was taken as $p<0.05$.

\section{Results}

During the 4-month study period, a total of 648 pupils who met the inclusion criteria were recruited. However, 76 were dropped as a result of unavailability of their parents or a substitute after several visits to their homes to fill in the questionnaires, leaving 572 subjects for the study. 
Table I shows some demographic characteristics of the subjects according to type of school. The majority $(62.8 \%)$ of the pupils were in the age range 6 - 9 years, with $37.2 \%$ in the range 10 12 years. The median age of the study population was 9 years. There were 284 males and 288 females, with a male/female ratio of $0.99: 1$. There was no striking difference in the proportion of males and females recruited into the study, but more females attended private schools than public schools $(p=0.04)$. More of the children from the higher socio-economic class attended private schools, while more from the lower socio-economic class attended public schools $(p=0.001)$.

A total of 132 pupils (23. $1 \%$ ) had Rutter scores of 10 and above on the teachers' scale, while $103(18.0 \%)$ had scores of 13 and above on the parents' scale. The difference was statistically significant $\left(\chi^{2}=19.8, p=0.001\right)$.

Type of school significantly affected the prevalence of behavioural problems among pupils according to the teachers' scale, which indicated that $52(16.7 \%)$ and 80 (30.8\%) children attending private and public schools, respectively, had behavioural problems $\left(\chi^{2}=5.89, p=0.001\right)$. The mean scores for all the children in private and public schools were 5.12 (standard deviation (SD) 6.25) and 7.4 (SD 6.41), respectively. This was statistically significant $(t=4.04, p=0.001)$.

The parents' scale indicated that 50 and 53 children attending the private and public schools, respectively, had behavioural problems. The difference was not statistically significant $\left(\chi^{2}=1.83\right.$, $p=0.18)$. Mean scores on that scale for all the children were 6.9 (SD 5.76) and 7.39 (SD 5.94) for the private and public schools, respectively $(t=0.68, p=0.5)$.
Table II shows the age and gender distribution of children with behavioural problems according to the teachers' and parents' scales. The proportion of children with behavioural problems increased with age, but there was no significant difference in prevalence according to age ( $p>0.05)$.

Significantly more males than females had behavioural problems according to both scales $(p=0.004$ and $p=0.001$ for teachers' and parents' scales, respectively).

Table III shows that according to the teachers' scale the proportion of children with behavioural problems was highest (31.4\%) in the lower social class. The differences in the proportions of children with abnormal behaviour between the social classes were significant. The parents' scale showed no significant differences in this respect.

Out of the 132 pupils with behavioural problems according to the teachers' scale, 90 (68.2\%) had antisocial features, 33 (25.0\%) neurotic features and $9(6.8 \%)$ undifferentiated behavioural problems, respectively (Table IV). Of all the children with antisocial behaviour, $68.9 \%$ were males, and of the children with neurotic features, $60.6 \%$ were females. Both scales indicated a significant difference in this type of problem between the genders $1 \chi^{2}=16.74, p=0.001$ and $\chi^{2}=14.41, p=0.002$ for teachers' and parents' scales, respectively). Type of school attended and age did not significantly influence the type of behavioural problems noted ( $p=0.05)$.

\section{Discussion}

This is one of the few childhood behavioural studies in Nigeria in which both teachers' and parents' scales have been used. The

\begin{tabular}{|c|c|c|c|}
\hline Variables & Private $(N=312)$ & Public $(N=260)$ & Total $(N=572)$ \\
\hline \multicolumn{4}{|l|}{ Age (yrs)* } \\
\hline $6-9$ & 226 & 133 & $359(62.8 \%)$ \\
\hline $10-12$ & 88 & 127 & $213(37.2 \%)$ \\
\hline \multicolumn{4}{|l|}{ Gender $^{\dagger}$} \\
\hline Male & 144 & 140 & $284(49.5 \%)$ \\
\hline Female & 168 & 120 & $288(50.5 \%)$ \\
\hline \multicolumn{4}{|c|}{ Social class ${ }^{\ddagger}$} \\
\hline Upper & 152 & 47 & 199 (34.8\%) \\
\hline Middle & 89 & 45 & 134 (23.4\%) \\
\hline Lower & 71 & 168 & 239 (41.7\%) \\
\hline Total & 312 & 260 & $572(100 \%)$ \\
\hline \multicolumn{4}{|l|}{$\begin{array}{l}p=0.001 \\
p=0.04\end{array}$} \\
\hline
\end{tabular}




\begin{tabular}{|c|c|c|c|c|c|}
\hline \multirow[b]{2}{*}{ Age group (yrs) } & \multirow{2}{*}{$\begin{array}{l}\text { Without behavioural } \\
\text { problems (\%) }\end{array}$} & \multicolumn{3}{|c|}{ With behavioural problems } & \multirow[b]{2}{*}{ Total } \\
\hline & & $M$ & $\mathrm{~F}$ & Total (\%) & \\
\hline $\begin{array}{l}\text { Teachers' scale* } \\
\quad 6-8\end{array}$ & $215(79.6)$ & 30 & 25 & $55(20.4)$ & 270 \\
\hline $9-10$ & $147(75.0)$ & 29 & 20 & $49(25.0)$ & 196 \\
\hline $11-12$ & $78(73.6)$ & 21 & 7 & $28(26.4)$ & 106 \\
\hline Total & $440(76.9)$ & 80 & 52 & $132(23.1)$ & 572 \\
\hline $\begin{array}{l}\text { Parents' scale }{ }^{\dagger} \\
6-8\end{array}$ & $231(85.6)$ & 26 & 13 & $39(14.4)$ & 270 \\
\hline $9-10$ & $155(79.1)$ & 28 & 13 & $41(20.9)$ & 196 \\
\hline $11-12$ & $83(78.3)$ & 14 & 9 & $23(21.7)$ & 106 \\
\hline Total & $469(82.0)$ & 68 & 35 & $103(18.0)$ & 572 \\
\hline $\begin{aligned} x^{*} \chi^{2} & =2.19, p=0.34 \\
\chi^{2} & =3.35, p=0.19 . \\
M & =\text { males } F=\text { females. }\end{aligned}$ & & & & & \\
\hline
\end{tabular}

Table III. Distribution of subjects within social class according to both scales

\begin{tabular}{|c|c|c|c|}
\hline Social class & With behavioural problems (\%) & Without behavioural problems (\%) & Total \\
\hline \multicolumn{4}{|c|}{ Teachers' scale* } \\
\hline Upper & $26(13.1)$ & $173(86.9)$ & 199 \\
\hline Middle & $31(23.1)$ & $103(76.9)$ & 134 \\
\hline Lower & $75(31.4)$ & $164(68.6)$ & 239 \\
\hline Total & $132(23.1)$ & $440(76.9)$ & 572 \\
\hline \multicolumn{4}{|c|}{ Parents' scale $\dagger$} \\
\hline Upper & $36(18.1)$ & $163(81.9)$ & 199 \\
\hline Middle & $24(17.9)$ & $110(82.1)$ & 134 \\
\hline Lower & $43(18.0)$ & $196(82.0)$ & 239 \\
\hline Total & $103(18.0)$ & $469(82.0)$ & 572 \\
\hline $\begin{aligned}{ }^{*} \chi_{2}^{2} & =20.5 p=0.001 \\
*^{* *} \chi & =0.002 p=0.999\end{aligned}$ & & & \\
\hline
\end{tabular}

majority of the pupils were in the age group 6 - 9 years, despite the fact that equal numbers of pupils were recruited from each class. This is not surprising, since age at school entry has dropped drastically, to the extent that some pupils complete their primary education by the age of 10 years.

The equal sex distribution noted in this study is encouraging. In an analysis of data on the Nigerian education sector, Moja ${ }^{20}$ documented gender disparity in the pattern of school enrollment, reporting low female enrollment in the northern region and low male enrollment in the south-eastern region. Some boys in the southern part are recruited as apprentices in workshops or marketplaces, while the girls in the north are denied education ostensibly on religious grounds.

There was a higher concentration of children from the upper social class in private schools, probably because the standard of education in the public schools is perceived as having deteriorated so much that those who can afford it send their children to private schools where teaching is considered to be better.

The overall prevalence of behavioural disorders according to the parents' scale was $18.8 \%$. This is similar to earlier reports 


\begin{tabular}{|c|c|c|c|}
\hline Type & Male (\%) & Female (\%) & Total \\
\hline \multicolumn{4}{|l|}{ Teachers' scale* } \\
\hline Antisocial & $62(68.9)$ & $28(31.1)$ & 90 \\
\hline Neurotic & $13(39.4)$ & 20160.6 & 33 \\
\hline Undifferentiated & $5(55.6)$ & $4(44.4)$ & 9 \\
\hline Total & $80(60.6)$ & $52(39.4)$ & 132 \\
\hline \multicolumn{4}{|l|}{ Parents' scale ${ }^{\dagger}$} \\
\hline Antisocial & $36(66.7)$ & $18(33.3$ & 54 \\
\hline Neurotic & $25(69.4)$ & $11(30.6)$ & 36 \\
\hline Undifferentiated & $7(53.8$ & $6(46.2)$ & 13 \\
\hline Total & 68166.0 & 35 (34.0) & 103 \\
\hline $\begin{array}{l}x^{2}=107 p=0.001 \\
t \chi^{2}=14.41 \quad p=0.002\end{array}$ & & & \\
\hline
\end{tabular}

by Adelekan et al. ${ }^{14}$ in Ilorin and higher than $11.8 \%$ reported by Eapen et $a l^{2}{ }^{2}$ in the United Arab Emirates. The prevalence of behavioural problems according to the teachers' scale was 23.1\%. This is higher than figures for schoolchildren in Saudi Arabia $^{5}$ (13.4\%), the United Arab Emirates ${ }^{21}$ (16.5\%) and other developed and developing countries. ${ }^{2,5,6,22}$ lloeje $^{23}$ from Enugu in south-eastern Nigeria found a prevalence of $22.6 \%$ in his study of children with sickle cell anaemia. There is considerable evidence that children with chronic illnesses have increased levels of emotional and psychological disturbances, which may amount to a psychiatric disorder. ${ }^{19,22}$ Our finding of a high prevalence of behavioural problems despite exclusion of children with sickle cell anaemia and other chronic illnesses is noteworthy. Environmental and socio-demographic factors may be responsible for this high figure.

The differences between the prevalences of behavioural problems reported by the teachers and the parents may be due to the protective attitude of parents towards their children, to the extent that a parent may not want to divulge his child's worrying behaviour to an outsider. Previous studies have also shown that parents and teachers report behavioural problems to different extents in the same children. ${ }^{1,16}$

Our finding that behavioural problems were more common in males $(60.6 \%)$ is consistent with earlier reports on gender difference in childhood behavioural disorder. ${ }^{2,3,6,14}$ Antisocial features were found to be more common in males, while neurotic problems were more common in females. These findings are in accordance with previous reports. ${ }^{2,4,5}$ We also found that behavioural problems were more common in the older children.
Behavioural problems have been reported to increase with age in some settings. ${ }^{21}$

The effect of socio-economic status was significant according to the teachers' scale $(p=0.001)$, children from the lower socioeconomic class having a higher prevalence of behavioural problems than those from the higher socio-economic class. The same tool has shown low socio-economic status to increase the risk of psychiatric disorders, ${ }^{19,21}$ and it is commonly reported to be a risk factor for psychiatric problems. ${ }^{24-26}$

It is interesting to note that the parents' scale revealed no association between behavioural disturbance and socioeconomic status. In our culture parents tend to protect their children, attempting to conceal some behavioural traits to avoid stigmatisation. Using the same tool, Eapen et al. noted no association with socio-economic status. ${ }^{2}$

Behavioural problems were more common in pupils from government primary schools than in those from private primary schools. This probably reflects the strong association between private schools and higher socio-economic class on the one hand and between government schools and lower socio-economic class on the other. If behavioural problems are more likely in the lower socio-economic classes, they are more likely in the government schools.

\section{Conclusion}

Our findings suggest that a significant number of children from Uyo have behavioural problems, with the prevalence of antisocial behaviour being high in both male and female schoolchildren. 
It also supports the possibility that parents report behavioural problems to a lesser extent than teachers. This state of affairs calls for government to provide comprehensive child mental health programmes. Among other advantages, these may reduce the rate of antisocial activity in Nigeria.

\section{References}

1. Kumpulainen K, Rasanen E, Henttonen I, et al. Children's behavioural/emotional problems: a comparison of parent's and teacher's reports for elementary school aged children. Eur Child Adolesc Psychiatry 1999; 4; 4 1-47.

2. Eapen V, Swadi H, Sabri S, Abou-Saleh M. Childhood behavioural disturbance in a community sample in Al-Ain, United Arab Emirates. East Mediterr Health J 2001 ; 7 : 428-434.

3. Hoeje S. Rutter's behaviour scale (B2) for children (teacher's scale): Validation and standardization for use on Nigerian children. J Trop Pediatr 1992; 38: 235-239.

4. Taanil A, Ebeling $\mathrm{H}$, lleikura $U$, Jarvelin $M$. Behavioural problems of eight year old children with or without intellectual disability. J Paediatr Neurol 2003; 1: 15-24.

5. Abolfotouh M. Behavioural disorders among school boys in South-Western Saudi Arabia. East Mediterr Health J 1997; 3: 274-283

6. Abiodun OA. Emotional illness in a pediatric population in Nigeria. J Trop Pediatr 1993; 39: 49-54

7. Rutter M. Why are London children so disturbed? Proc R Soc Med 1973; 66: 1221 1229

8. Aronu A E, Ojinnaka NC. Psychiatric morbidity among parents of children with epilepsy in Enugu, Nigeria. Neurology Asia 2009; 14: 15-20.

9. Rutter $M$. A children's behaviour questionnaire for completion by teachers: preliminary findings. J Child Psychol Psychiatry 1967; 8: 1-11.

10. Goyett CH, Conner CK, Ulrich RF. Normative data on revised Cornner's parents and teachers rating scale. J Abnorm Child Psychol 1998; 8: 471-490.

11. Rishel C, Greeno C, Marcus S, Shear M, Anderson C. Use of the child behaviou checklist as a diagnostic screening tool in community mental health. Research on Social Work Practice 2005; 15: 195-203
12. Omigbodun $O$, Gureje O, Ikuesan B, Gater R, Adebayo E. Psychiatric morbidity in a Nigerian paediatric primary care service: a comparison of two screening instruments. Social Psychiatry Psychiatr Epidemiol 1996; 31 : 186-193.

13. Ohaere J, Odejide $\bigcirc$, Gureje $\bigcirc$, Olatawura $\bigcirc$. Psychiatric morbidity among children attending health facilities in primary health care in a rural Nigerian community. Nig Med J 1994; 26: 68-73

14. Adelekan M, Ndom R, Ekpom, Oluboka O. Epidemiology of childhood behavioural disorders in Ilorin, Nigeria - findings from parental reports. West Afr J Med 1999; 18: $39-48$

15. Puura K, Almqvist F, Tamminen T, et al. Psychiatric disturbances among prepubertal children in Southern Finland. Social Psychiatry Psychiatr Epidemiol 1998; 33: $310-$ 318.

16. Kumpulainen K, Räsänen E. Symptoms and deviant behavior among eight-year-olds as predictors of referral for psychiatric evaluation by age 12. Psychiatr Serv 2002; 53: 201-206.

17. Gureje O, Omigbodum OO, Gater R, Acha R A, Ikuesan B A, Morris J. Psychiatric disorders in a pediatric primary care clinic. BrJ Psychiatry 1994; 165: 527-530.

18. Ebigbo PD, Okwaraji F, Ekwo JE. A study of norm reference indicators of the Draw-a Person test in Nigeria. Journal of Research in Special Education 200 1; 4 (2b): 20-28

19. Oyedeji G. Social-economic and cultural background of hospitalized children in llesha. Nig J Paediatr 1985; 12:111-117

20. Moja T. Nigeria Education Sector Analysis: An Analytical Synthesis of Performance and Main Issues. Washington DC: World Bank Document 2000.

21. Eapen V, al Gazali L, Bin-Othman S, Abou-Saleh M. Mental health problems among school children in United Arabs Emirate: Prevalence and risk factors. J Am Child Adolesc Psychiatry 1998; 37: 880-886

22. Ibekwe RC, Ojinnaka NC, lloeje SO. Factors influencing academic performance of school children with epilepsy. J Trop Pediatr 2007; 53: 338-343.

23. Hoeje S. Psychiatric morbidity among children with sickle cell disease.Dev Med Child Neurol 1991; 33: 1087-1094.

24. Lin $Y Q$, Ebrahim $G$. Frequency of behaviour disorder and related factors in school children in Lusaka. J Trop Pediatr 1991; 37: 303-309.

25. Iloeje SO, Ojinnaka NC, Onyema GM. Depressive symptoms in adolescent and young adults with epilepsy. Journal of College of Medicine 2002; 5(1): 42-44

26. Harland P, Reijneveld S, Brugman E, Verloove-Vanhorick S, Verhulst F. Family factors and life events as risk factors for behavioural and emotional problems in children. Eur Child Adolesc Psychiatry 2002; 11: 176-184. 